\title{
1 Compound-Specific Chlorine Isotope Fractionation 2 in Biodegradation of Atrazine ${ }^{\dagger}$
}

3 Christina Lihla,b, Benjamin Heckela,b, Anna Grzybkowskac, Agnieszka Dybala-Defratykac,

4 Violaine Ponsin ${ }^{\mathrm{d}, \mathrm{e}}$, Clara Torrentód,f, Daniel Hunkeler ${ }^{\mathrm{d}}$, Martin Elsner ${ }^{\mathrm{a}, \mathrm{b}, *}$

5 a Institute of Groundwater Ecology, Helmholtz Zentrum München, Ingolstädter Landstraße 1, 85764

6 Neuherberg, Germany

7 b Chair of Analytical Chemistry and Water Chemistry, Technical University of Munich, Marchioninistraße

$8 \quad 17,81377$ Munich, Germany

9 c Institute of Applied Radiation Chemistry, Faculty of Chemistry, Lodz University of Technology,

10 Zeromskiego 116, 90-924 Lodz, Poland

11 d Centre of Hydrogeology and Geothermics (CHYN), University of Neuchâtel, 2000 Neuchâtel, Switzerland

12 e Département des sciences de la Terre et de l'atmosphère, Université du Québec à Montréal, 201 avenue

13 du Président Kennedy, Montréal, QC, Canada

14 f Grup MAiMA, Departament de Mineralogia, Petrologia i Geologia Aplicada, Facultat de Ciències de la

15 Terra, Universitat de Barcelona (UB), C/ Martí i Franquès s/n, 08028, Barcelona, Spain.

16 * Corresponding Author: Phone: +49 89/2180-78231. E-mail: m.elsner@tum.de

$17+$ Electronic Supplementary Information (ESI) available: Information concerning the HPLC temperature

18 programs, two Figures and one Table illustrating the GC-qMS method optimization for chlorine analysis,

19 one Table illustrating the method comparison of the GC-qMS for chlorine analysis, one Figure and one

20 Table considering $\mathrm{H}$-abstraction during chlorine CSIA, two Figures illustrating the results of HPLC 21 concentration analysis. 
22 KEYWORDS: hydrolysis, oxidative dealkylation, compound-specific isotope analysis, chlorine

23 isotope effect, Arthrobacter, Rhodococcus

24 Graphical Abstract:

25

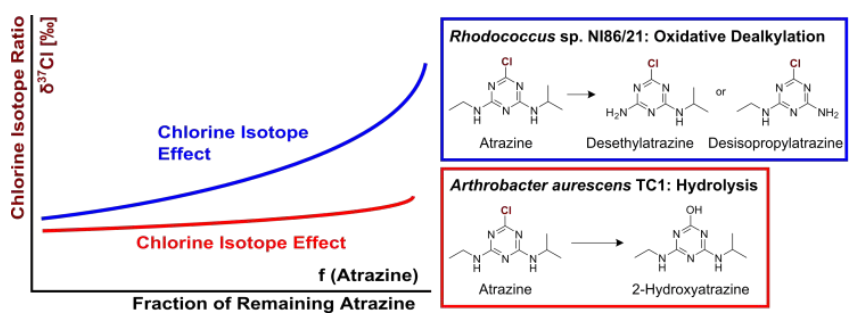


Atrazine is an important chlorinated micropollutant. Although degradable via different pathways (dealkylation and hydrolytic dechlorination), it is often recalcitrant and persists in groundwater. To assess and understand its degradation pathways, compound-specific carbon and nitrogen isotope analysis has been advanced, but information from chlorine isotope fractionation has been missing until today. This study explores the added benefit of chlorine isotope fractionation as indicator of natural atrazine transformation. Together with carbon and nitrogen isotope analysis, this enables a multi-element approach which can improve source identification and differentiation of microbial transformation pathways in the environment.

\section{ABSTRACT}

Atrazine is a frequently detected groundwater contaminant. It can be microbially degraded by oxidative dealkylation or by hydrolytic dechlorination. Compound-specific isotope analysis is a powerful tool to assess its transformation. In previous work, carbon and nitrogen isotope effects were found to reflect these different transformation pathways. However, chlorine isotope fractionation could be a particularly sensitive indicator of natural transformation since chlorine isotope effects are fully represented in the molecular average while carbon and nitrogen isotope effects are diluted by non-reacting atoms. 
Therefore, this study explored chlorine isotope effects during atrazine hydrolysis with Arthrobacter aurescens TC1 and oxidative dealkylation with Rhodococcus sp. NI86/21.

Dual element isotope slopes of chlorine vs. carbon isotope fractionation $\left(\wedge{ }^{\text {Arthro }}{ }_{\mathrm{C} / \mathrm{C}}=1.7\right.$ \pm 0.9 vs. $\left.\wedge \wedge^{\text {Rhodo }} \mathrm{Cl} / \mathrm{C}=0.6 \pm 0.1\right)$ and chlorine vs. nitrogen isotope fractionation $\left(\wedge^{\text {Arthro }}{ }_{\mathrm{Cl} / \mathrm{N}}=-\right.$ $1.2 \pm 0.7$ vs. $\wedge^{\text {Rhodo }} \mathrm{Cl/N}=0.4 \pm 0.2$ ) provided reliable indicators of different pathways.

51 Observed chlorine isotope effects in oxidative dealkylation $\left(\varepsilon_{\mathrm{Cl}}=-4.3 \pm 1.8 \%\right.$ o $)$ were 52 surprisingly large, whereas in hydrolysis $\left(\varepsilon_{C l}=-1.4 \pm 0.6 \%\right)$ they were small, indicating 53 that $\mathrm{C}-\mathrm{Cl}$ bond cleavage was not the rate-determining step. This demonstrates the 54 importance of constraining expected isotope effects of new elements before using the 55 approach in the field. Overall, the triple element isotope information brought forward here 56 enables a more reliable identification of atrazine sources and degradation pathways. 
59 The herbicide atrazine has been used in agriculture to inhibit growth of broadleaf and

60 grassy weeds ${ }^{1}$. In the U.S. atrazine was the second most commonly used herbicide in

612012 and is still in use today ${ }^{2}$. In the European Union atrazine was banned in $2004^{3}$, but

62 together with its metabolites it is still frequently detected at high concentrations in

63 groundwater 4 . 5 . The massive and widespread use has led to a wide-ranging presence of

64 atrazine in the environment, which can have harmful effects on living organisms and

65 humans $^{6}$. Therefore, the environmental fate of atrazine is of significant concern and much

66 attention has been directed at detecting and enhancing its natural biodegradation.

67 However, assessing microbial degradation of atrazine in the environment is challenging with conventional methods like concentration analysis. Sorption and remobilization of the parent compound and its metabolites, as well as further transformation of the metabolites

70 inevitably lead to fluctuations in concentrations ${ }^{7-10}$, which make it difficult to assess the 71 net extent of atrazine degradation in the field.

72 In recent years, compound-specific isotope analysis (CSIA) has been proposed as an

73 alternative approach to detect and quantify the degradation of atrazine ${ }^{11-13}$.

74 In contrast to, and complementary to traditional methods, CSIA informs about 75 transformation without the need to detect metabolites. The reason is that during 76 (bio)chemical transformations molecules with heavy isotopes are typically enriched in the 77 remaining substrate since their bonds are more stable and, therefore, usually react slower 
than molecules containing light isotopes (normal kinetic isotope effect). The ratios of heavy to light isotopes (e.g. ${ }^{13} \mathrm{C} /{ }^{12} \mathrm{C}$ for carbon) in the remaining substrate, therefore, change during transformation. Observing such changes can be used as direct (and concentration-independent) indicator of degradation ${ }^{14,15}$.

Isotope values are reported in the $\delta$-notation relative to an international reference

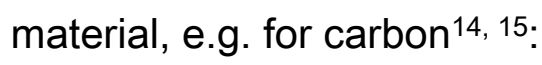

$$
\delta^{13} \mathrm{C}=\left[\left({ }^{13} \mathrm{C} /{ }^{12} \mathrm{C}\right)_{\text {Sample }}-\left({ }^{13} \mathrm{C} /{ }^{12} \mathrm{C}\right)_{\text {Reference }}\right] /\left({ }^{13} \mathrm{C} /{ }^{12} \mathrm{C}\right)_{\text {Reference }}
$$

The magnitude of the degradation-induced isotope fractionation depends on different factors, which can make isotope ratios of specific elements particularly attractive to observe degradation-induced isotope fractionation. To this end, first, an element needs to be directly involved in the (bio)chemical reaction. For example, a carbon isotope effect would be quite generally expected in organic molecules, whereas a chlorine isotope effect would be primarily expected if a $\mathrm{C}-\mathrm{Cl}$ bond is cleaved. Second, isotope fractionation depends on the underlying kinetic isotope effect (see above), but also on the extent to which this effect is represented in the molecular average isotope fractionation described by the enrichment factor $\varepsilon$ (see below). Atrazine, for example, contains only one chlorine atom but eight carbon and five nitrogen atoms. Hence, chlorine isotope effects at the reacting position are fully represented in the molecular average, whereas position-specific carbon and nitrogen isotope effects are diluted by non-reacting atoms ${ }^{14,15}$. 
Most of the publications studying the chemical mechanisms of abiotic and microbial atrazine degradation have focused on the analysis of carbon $\left({ }^{13} \mathrm{C} /{ }^{12} \mathrm{C}\right)$ and nitrogen $\left({ }^{15} \mathrm{~N} /{ }^{14} \mathrm{~N}\right)$ isotope fractionation. Thereby, $\varepsilon$-values in the range of $-5.4 \%$ to $-1.8 \%$ for carbon and $-1.9 \%$ to $3.3 \%$ for nitrogen were observed ${ }^{9}, 10,16,17$. Chlorine isotope effects for microbial atrazine degradation were so far not reported due to analytical challenges ${ }^{18}$ : Until recently ${ }^{19,20}$, suitable methods were not available for chlorine isotope analysis of atrazine. However, from the magnitude of chlorine isotope effects observed for dechlorination of trichloroethenes $(-5.7 \%$ to $-3.3 \%$, where intrinsic isotope effects are diluted by a factor of three $\left.{ }^{21}\right)$, very large chlorine enrichment factors $\varepsilon_{\mathrm{Cl}}(-8 \%$ to $-10 \%$ or even larger) could potentially occur for a $\mathrm{C}-\mathrm{Cl}$ bond cleavage in atrazine. For example, enzymatic hydrolysis of the structural homologue ametryn (atrazine structure with a $\mathrm{SCH}_{3}$ instead of a $-\mathrm{Cl}$ group) yielded a sulfur isotope enrichment factor $\varepsilon_{S}$ of $14.7 \%$ $\pm 1.0 \%{ }^{17}$. If the cleavage of carbon-chlorine bonds is involved in the ratedetermining step of a (bio)transformation, chlorine isotope effects could, therefore, enable a particularly sensitive detection of natural transformation processes by compoundspecific (i.e., molecular average) isotope analysis.

The measurement of chlorine isotope fractionation is attractive for yet another reason multiple element isotope analysis bears potential for a better distinction of sources and transformation pathways. From isotope analysis of one element alone, it is difficult to distinguish sources of a particular compound, or competing transformation pathways that 
117 may lead to metabolites of different toxicity ${ }^{15}$. For example, two different microbial

118 transformation pathways can lead to the degradation of atrazine in the environment.

119 Hydrolysis forms the nontoxic dehalogenated product 2-hydroxyatrazine (HAT) whereas

120 oxidative dealkylation degrades atrazine to the still herbicidal products desethyl- (DEA)

121 or desisopropylatrazine (DIA) ${ }^{22,23}$. Prominent examples for microorganisms catalyzing

122 these pathways are Arthrobacter aurescens TC1 and Rhodococcus sp. NI86/21 (see

123 Figure 1). A. aurescens TC1 was directly isolated from an atrazine-contaminated soil ${ }^{24}$.

124 By expressing the enzyme TrzN, it is capable of performing hydrolysis of atrazine ${ }^{24,25}$.

125 Rhodococcus sp. NI86/21 uses a cytochrome P450 system for catalyzing oxidative

126 dealkylation of atrazine ${ }^{26}$.

Arthrobacter aurescens TC1 (TrzN): Hydrolysis

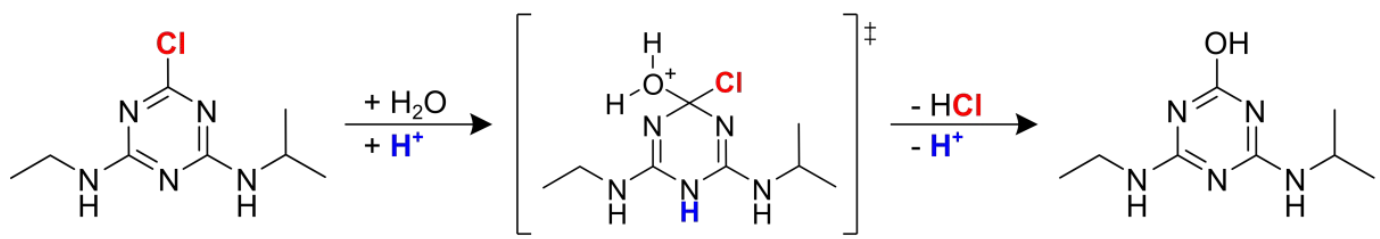

Atrazine

Meisenheimer Complex

2-Hydroxyatrazine

Rhodococcus sp. NI86/21 (Cytrochrome P450): Oxidative Dealkylation

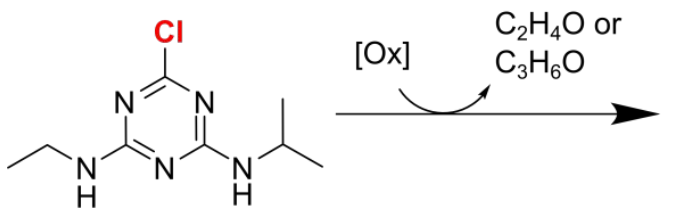

Atrazine<smiles>CC(C)Nc1nc(N)nc(Cl)n1</smiles>

Desethylatrazine<smiles>CCNc1nc(N)nc(Cl)n1</smiles>

Desisopropylatrazine

Figure 1. Microbial degradation of atrazine by Arthrobacter aurescens TC1 and Rhodococcus sp. NI86/21 (adapted from Meyer et al. ${ }^{9}$ and Meyer \& Elsner ${ }^{10}$ ). 

differences were observed in nitrogen isotope effects ${ }^{9,10,16,17 . ~ P l o t t i n g ~ t h e ~ c h a n g e s ~ o f ~}$ isotope ratios of these two elements relative to each other results in the regression slope $\Lambda$ for carbon and nitrogen 27,28

$134 \Lambda_{C / N}=\Delta \delta^{15} \mathrm{~N} / \Delta \delta^{13} \mathrm{C} \approx \varepsilon_{N} / \varepsilon_{C}$

135 Hence, dual element $(\mathrm{C}, \mathrm{N})$ isotope trends for oxidative dealkylation of atrazine with Rhodococcus sp. NI86/21 ( $\left(\wedge^{\text {Rhodo }} \mathrm{C/N}=0.4 \pm 0.1\right)^{16}$ were significantly different compared to hydrolysis with $A$. aurescens $\mathrm{TC} 1\left(\wedge \wedge^{\text {Arthro }} \mathrm{C} / \mathrm{N}=-0.6 \pm 0.1\right)^{9}$ offering an opportunity to 138 distinguish atrazine degradation pathways in the field. However, in environmental 139 assessments it is advantageous to have isotopic information of as many elements as 140 possible in order to distinguish degradation pathways and sources at the same time $e^{29-31}$.

141 Therefore, information from a third element, chlorine, would be highly valuable. Also on

142 the mechanistic end, information gained from a change in the chlorine isotope value could

143 lead to a more reliable differentiation of transformation pathways and contribute to a better

144 mechanistic understanding of the underlying chemical reaction ${ }^{31}$. Along these lines, triple

145 element (3D) isotope analysis was already accomplished for chlorinated alkanes ${ }^{31,32}$ and 146 alkenes ${ }^{33,34}$.

147 Until now, however, compound-specific chlorine isotope analysis has not been 148 accessible so that chlorine isotope ratio changes for hydrolysis of atrazine have only been 149 analyzed in abiotic systems or via computational calculations ${ }^{35}$, 36. For oxidative 
dealkylation, chlorine isotope effects have, so far, not been studied. Recently a GC-qMS method for chlorine isotope analysis of atrazine has been brought forward ${ }^{20}$ which offers the opportunity to enable deeper mechanistic insights into its transformation processes.

153 Therefore, our objective was to analyze carbon, nitrogen and chlorine isotope effects associated with the biodegradation of atrazine via hydrolysis with $A$. aurescens TC1 and via oxidative dealkylation with Rhodococcus sp. NI86/21. In addition, we computationally

156 predicted the chlorine isotope effect associated with hydrolysis and oxidative dealkylation

157 for comparison. Further, we evaluated whether the additional information from chlorine

158 isotope fractionation is a particularly sensitive indicator for transformation processes and

159 whether it can confirm previously proposed mechanisms of different pathways. With this

160 study, we bring forward information about degradation-induced chlorine isotope

161 fractionation of atrazine as a basis to apply triple element (3D) isotope analysis in

162 environmental assessments.

164 Bacterial strains and cultivation. A. aurescens strain TC1 was grown in mineral salt

165 medium supplemented with approx. $20 \mathrm{mg} / \mathrm{L}$ of atrazine according to the protocol of 166 Meyer et al. ${ }^{9}$ Likewise, Rhodococcus sp. strain NI86/21 was cultivated in autoclaved 167 nutrient broth $\left(8 \mathrm{~g} / \mathrm{L}\right.$, Difco $\left.{ }^{\mathrm{TM}}\right)$ with approx. $20 \mathrm{mg} / \mathrm{L}$ of atrazine according to the protocol 168 of Meyer et al. ${ }^{16}$. In the late-exponential growth phase the strains were harvested via centrifugation (4000 rpm, $15 \mathrm{~min}$ ). For the start of the degradation experiments, cell 
pellets of each strain were transferred to $400 \mathrm{~mL}$ fresh media and atrazine was added to

171 achieve a starting concentration of $20 \mathrm{mg} / \mathrm{L}$. All experiments were performed in triplicate

172 at $21^{\circ} \mathrm{C}$ on a shaker at $150 \mathrm{rpm}$. Control experiments, which were performed without the

173 bacterial strains, did not show any degradation of atrazine.

174 Concentration measurements via HPLC. The process of atrazine degradation was 175 monitored by concentration measurements. For analysis, $1 \mathrm{~mL}$ samples were taken and 176 filtered through a $0.22 \mu \mathrm{m}$ filter. Atrazine and its degradation products were directly 177 analyzed using a Shimadzu UHPLC-20A system, which was equipped with an ODS 178 column 30 (Ultracarb $5 \mu \mathrm{M}, 150 \times 4.6 \mathrm{~mm}$, Phenomenex). After sample injection $(10 \mu \mathrm{L})$

179 an adequate gradient program (see SI) was used for compound separation. The oven temperature was set to $45^{\circ} \mathrm{C}$ and the compounds were detected by their UV absorbance at $222 \mathrm{~nm}$. Quantitation was performed by the software "Lab Solutions" based on internal calibration curves.

Preparation of samples for isotope analysis. According to the protocol of Meyer et al. ${ }^{9}$ between 10 and $260 \mathrm{~mL}$ of sample were taken for isotope analysis of atrazine at every sampling event. After centrifugation (15 min, $4000 \mathrm{rpm}$ ) the supernatant was collected in a new vial. Subsequently, samples were extracted by adding dichloromethane $(5-130 \mathrm{~mL})$ and shaking the vial for at least 20 min. The sample extracts were dried at room temperature under the fume hood. Afterwards, the dried extracts were dissolved in ethyl acetate to a final atrazine concentration of approx. $200 \mathrm{mg} / \mathrm{L}$. 

nitrogen was adapted from the studies of Meyer et al. ${ }^{9},{ }^{16}$. A TRACE GC Ultra gas chromatograph hyphenated with a GC-III combustion interface and coupled to a Finnigan MAT253 isotope ratio mass spectrometer (GC-C-IRMS, all Thermo Fisher Scientific) was used. Each sample was analyzed in triplicate. Sample injection (2-3 $\mu \mathrm{L})$ was performed by a Combi-PAL autosampler (CTC Analysis). The injector had a constant temperature of $220^{\circ} \mathrm{C}$, was equipped with an "A" type packed liner for large volume injections (GL Sciences) and was operated for $1 \mathrm{~min}$ in splitless and then in split mode (split ratio 1:10) with a flow rate of $1.4 \mathrm{~mL} / \mathrm{min}$. For peak separation, the $\mathrm{GC}$ oven was equipped with a DB-5 MS column $(30 \mathrm{~m} \times 0.25 \mathrm{~mm}, 1 \mu \mathrm{m}$ film thickness, Agilent). The temperature program of the oven started at $65^{\circ} \mathrm{C}$ (held for $1 \mathrm{~min}$ ), ramped at $20^{\circ} \mathrm{C} / \mathrm{min}$ to $180^{\circ} \mathrm{C}$ 201 (held for $10 \mathrm{~min}$ ) and ramped again at $15^{\circ} \mathrm{C} / \mathrm{min}$ to $230^{\circ} \mathrm{C}$ (held for $8 \mathrm{~min}$ ). In the 202 combustion interface, a GC Isolink II reactor (Thermo Fisher Scientific) was installed, 203 which was operated at a temperature of $100{ }^{\circ} \mathrm{C}$. After combustion of the analytes to $\mathrm{CO}_{2}$ 204 and subsequent reduction of any nitrogen oxides, the compounds were analyzed as $\mathrm{CO}_{2}$ 205 for carbon and $\mathrm{N}_{2}$ for nitrogen isotope measurements. Three pulse of $\mathrm{CO}_{2}$ or $\mathrm{N}_{2}$, 206 respectively, were introduced at the beginning and at the end of each run as monitoring 207 gas. Beforehand, these monitoring gases were calibrated against RM8563 $\left(\mathrm{CO}_{2}\right)$ and 208 NSVEC $\left(\mathrm{N}_{2}\right)$, which were supplied by the International Atomic Energy Agency (IAEA). 209 The analytical uncertainty $2 \sigma$ was $\pm 0.5 \%$ for carbon isotope values and $\pm 1.0 \%$ for 210 nitrogen isotope values. 
211 Isotope analysis of chlorine. For chlorine isotope analysis of atrazine, a 7890A gas

212 chromatograph coupled to a 5975C quadrupole mass spectrometer (GC-qMS, both

213 Agilent) was used. Sample injection ( $2 \mu \mathrm{L})$ was performed by a Pal Combi-xt autosampler

214 (CTC Analysis). For the injector and the GC oven, the same parameters as for carbon

215 and nitrogen isotope analysis were used with the exception that a different liner type, a

216 "FocusLiner" (SGE), was used. The ion source had a constant temperature of $230^{\circ} \mathrm{C}$ and

217 the quadrupole of $150^{\circ} \mathrm{C}$. Prior to sample analysis, the method of Ponsin et al. ${ }^{20}$ was

218 tested and optimized for our instrument (see details in SI). Chlorine isotope ratios were

219 evaluated by monitoring the mass-to-charge ratio $\mathrm{m} / \mathrm{z}$ of $202 / 200$. Standards and samples

220 were measured ten times each and uncertainties were reported as standard deviation.

221 Results were only evaluated if the peak areas of samples were inside a defined linearity

222 range (peak area of $1.2 \times 10^{8}-3.0 \times 10^{8}$ for $\mathrm{m} / \mathrm{z} 200$ ). Inside the linearity range, the

223 determined precision of the method is associated with a maximal deviation of $\pm 1.1 \%$. For

224 analysis, the samples were diluted with ethyl acetate to a final concentration of

225 approx. $75 \mathrm{mg} / \mathrm{L}$ and measured with a dwell time of $100 \mathrm{~ms}$. Correction of the chlorine

226 isotope values relative to Standard Mean Ocean Chloride (SMOC) was performed by an

227 external two-point calibration with characterized standards of atrazine (Atr $\# 4 \delta^{37} \mathrm{Cl}=$ -

$228 \quad 0.89 \%$ and $\operatorname{Atr} \# 11 \delta^{37} \mathrm{Cl}=+3.59 \%$ \% ${ }^{37}$. To this end, the standards were measured at the

229 beginning, in between and at the end of each sequence. 

was achieved by the Rayleigh equation, which describes the gradual enrichment of the residual substrate fraction $f$ with molecules containing heavy isotopes, as expressed by

233 isotope values according to eq. ${ }^{15}$, 38. For example, for chlorine:

$$
\ln \left[\left(\delta^{37} \mathrm{Cl}+1\right) /\left(\delta^{37} \mathrm{Cl}_{0}+1\right)\right]=\varepsilon_{\mathrm{Cl}} \cdot \ln \mathrm{f}
$$

235 Here $\delta^{37} \mathrm{Cl}_{0}$ refers to the chlorine isotope value at the starting point $(\mathrm{t}=0)$ of an 236 experiment. Regression slopes $\Lambda$ of dual element isotope plots were obtained by plotting 237 isotope ratios of two different elements against each other, e.g. carbon vs. nitrogen (see 238 eq. 2). The uncertainties of the calculated $\varepsilon$-values and $\Lambda$-values are reported as $95 \%$ 239 confidence intervals $(\mathrm{Cl})$. Furthermore, (apparent) kinetic isotope values, $(A) \mathrm{KIE}_{\mathrm{Cl}}$, that 240 express the ratio of reaction rates ${ }^{35} \mathrm{k}$ and ${ }^{37} \mathrm{k}$ of heavy and light isotopologues, 241 respectively,

$242 \quad \mathrm{KIE}_{\mathrm{Cl}}={ }^{35} \mathrm{k} /{ }^{37} \mathrm{k}$

243 were calculated according to Elsner et al. ${ }^{15}$ by converting $\varepsilon_{\mathrm{Cl}}$-values into $(\mathrm{A}) \mathrm{KIE}_{\mathrm{Cl}}$ and 244 taking into account that atrazine contains only one chlorine atom $(n=1)$ :

$245 \quad(\mathrm{~A}) \mathrm{KIE}_{\mathrm{Cl}}=1 /\left(\mathrm{n} \times \varepsilon_{\mathrm{Cl}}+1\right)$ 
molecule in the oxidative dealkylation reaction promoted by permanganate and the

250 hydronium ion, respectively. Furthermore, we considered hydrolysis under

251 acidic/enzymatic, neutral and alkaline conditions. All molecular structures and analytical

252 vibrational frequencies for involved reactant complexes and transition states were taken

253 from a previous study ${ }^{16}$. Chlorine kinetic isotope effects on dealkylation were calculated

254 using the complete Bigeleisen equation ${ }^{39}$ implemented in the ISOEFF program ${ }^{40}$ at

$255300 \mathrm{~K}$. Additional isotope effects predictions for hydrolysis under acidic as well as neutral

256 conditions were performed following the previous computational protocol ${ }^{36}$. The tunneling

257 contributions to the overall kinetic isotope effect were omitted.

258 RESULTS \& DISCUSSION

259 Observation of normal chlorine isotope effects in biotic hydrolysis and oxidative

260 dealkylation. Atrazine degradation by $A$. aurescens TC1 resulted in the metabolite 2-

261 hydroxyatrazine, whereas the metabolites DEA and DIA were observed for

262 Rhodococcus sp. NI86/21 (see Figure S4 and S5 in the SI). Detection of these expected

263 degradation products (Figure 1) demonstrates that hydrolysis and oxidative dealkylation

264 were the underlying biochemical reactions during atrazine degradation, respectively. In

265 both biodegradation experiments - biotic hydrolysis with $A$. aurescens TC1 and oxidative

266 dealkylation with Rhodococcus sp. NI86/21 - normal chlorine isotope fractionation was

267 observed (see Figure 2A). In the three replicates of hydrolytic degradation by

268 A. aurescens TC1 $90 \%, 90 \%$ and $60 \%$ transformation of atrazine was reached after 
269 approx. $26 \mathrm{~h}$, respectively (see SI, Figure S4). Evaluation of $\delta^{37} \mathrm{Cl}$ values during biotic

270 hydrolysis according to Equation 3 resulted in a small normal isotope effect of $\varepsilon_{\mathrm{Cl}}=-1.4$

$271 \pm 0.6 \%$. In oxidative dealkylation with Rhodococcus sp. NI86/21 approx. $90 \%$

272 degradation was reached after approx. $186 \mathrm{~h}$ in all three replicates (see SI, Figure S5).

273 Evaluation of changes in chlorine isotope ratios resulted in a surprisingly large normal

274 isotope effect of $\varepsilon_{\mathrm{Cl}}=-4.3 \pm 1.8 \%$ o considering that the $\mathrm{C}-\mathrm{Cl}$ bond is not broken during

275 the reaction (see Figure 1). In a next step, carbon and nitrogen isotope effects were

276 therefore analyzed to confirm whether the same reactions mechanisms are at work as

277 observed in previous studies ${ }^{9,16}$. 

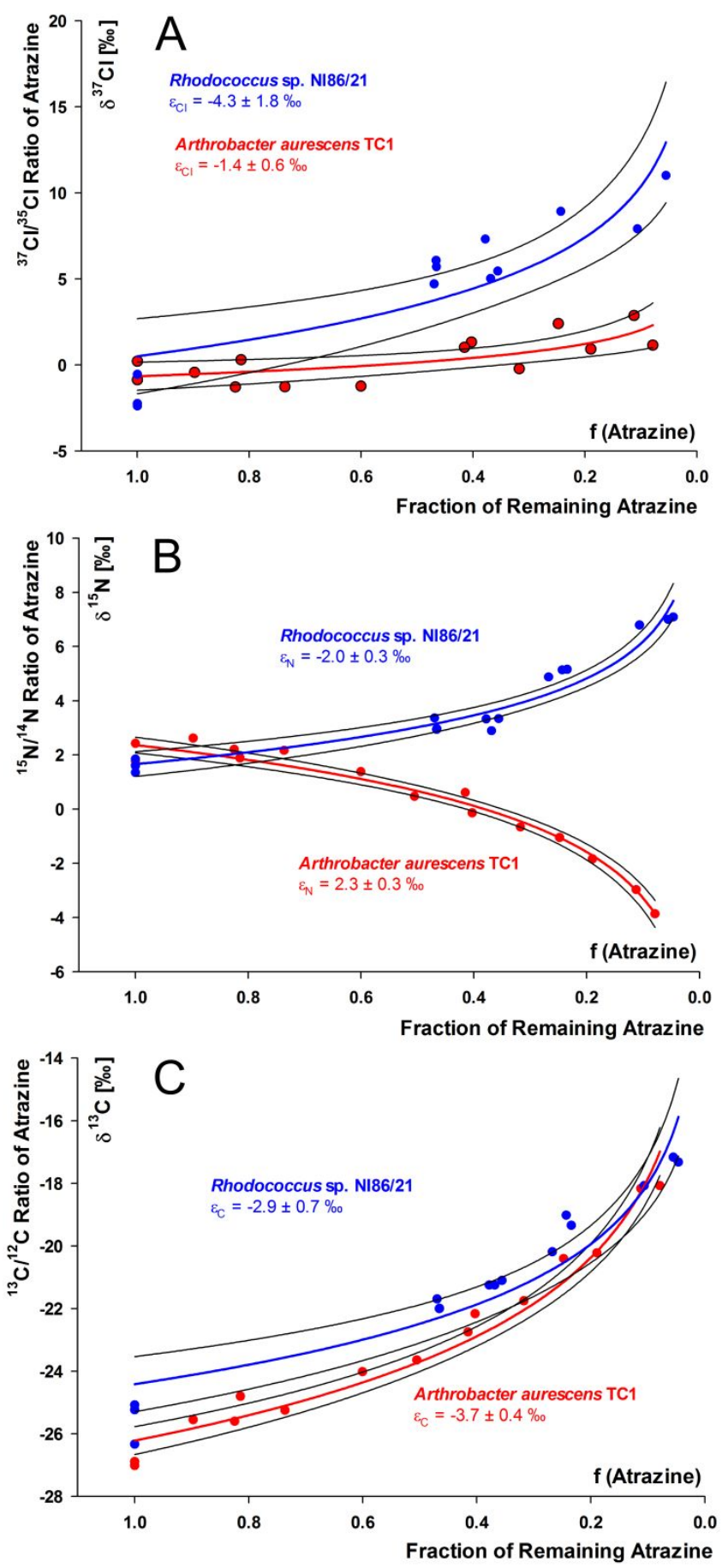

279 Figure 2. Isotope fractionation of $(A)$ chlorine, $(B)$ nitrogen and $(C)$ carbon during 280 microbial degradation of atrazine by $A$. aurescens TC1 (red) and Rhodococcus sp. 
NI86/21 (blue) and corresponding enrichment factors $\varepsilon$ evaluated according to eq. 3. (The $95 \%$ confidence intervals are given as values and as black lines). Carbon and nitrogen isotope fractionation for atrazine degradation by $A$. aurescens TC1 and Rhodococcus sp. NI86/21 was consistent with previous studies: Both experiments showed significant changes in isotope ratios (see Figure $2 \mathrm{~B}$ and $\mathrm{C}$ ). For hydrolysis with A. aurescens TC1, an inverse nitrogen isotope effect $\left(\varepsilon_{N}=2.3 \pm 0.3 \%\right.$ ) and a normal carbon isotope effect $\left(\varepsilon_{C}=-3.7 \pm 0.4 \%\right.$ ) were observed, which were slightly smaller compared to the results of a former publication of Meyer et al. $\left(\varepsilon_{N}=3.3 \pm 0.4 \%\right.$, $\varepsilon_{C}=$ $5.4 \pm 0.6 \%)^{9}$, but gave the same dual element isotope plot $\left(\wedge^{\text {Arthro }} \mathrm{C/N}=-0.6 \pm 0.1\right)$ confirming that the same mechanism was at work (see Figure $3 \mathrm{~A}$ ). nitrogen isotope effect of $\varepsilon_{N}=-2.0 \pm 0.3 \%$ and a normal carbon isotope effect of $\varepsilon_{C}=-$ $2.9 \pm 0.7 \%$. These $\varepsilon$-values are similar to those published by Meyer $\&$ Elsner ${ }^{10}\left(\varepsilon_{N}=-1.5\right.$ $\pm 0.3 \%$, $\varepsilon_{C}=-4.0 \pm 0.2 \%$ ) and Meyer et al. ${ }^{16}\left(\varepsilon_{N}=-1.4 \pm 0.3 \%\right.$, $\left.\varepsilon_{C}=-3.8 \pm 0.2 \% 0\right)$. The slightly more pronounced nitrogen isotope fractionation in this study can probably be 297 attributed to the fact that oxidation was primarily observed at the $\mathrm{C}-\mathrm{H}$ bond adjacent to 298 the nitrogen atom ( $\alpha$-position of the ethyl or isopropyl group, see closed mass balance in 299 Figure S5 in the SI) ${ }^{16}$. In the study of Meyer et al. ${ }^{16} 48 \%$ of the oxidation was observed 300 at the $\beta$-position of the ethyl or isopropyl group resulting in a smaller nitrogen isotope 
301 fractionation effect. The obtained regression slope of $\wedge^{\text {Rhodo }} \mathrm{C} / \mathrm{N}=0.7 \pm 0.1$ in this study is 302 slightly larger than the previously reported regression slopes $\left(\wedge^{\text {Rhodo }} \mathrm{C} / \mathrm{N}=0.4 \pm 0.1\right)^{10,16}$ 303 which may again be explained by the small difference in average nitrogen isotope effects.

304 Also here, however, the similar dual element isotope trend confirms that in this study 305 atrazine was transformed by the same mechanism as in Meyer et al. ${ }^{16}$ leading to the 306 observed oxidative dealkylation products by Rhodococcus sp. NI86/21. 

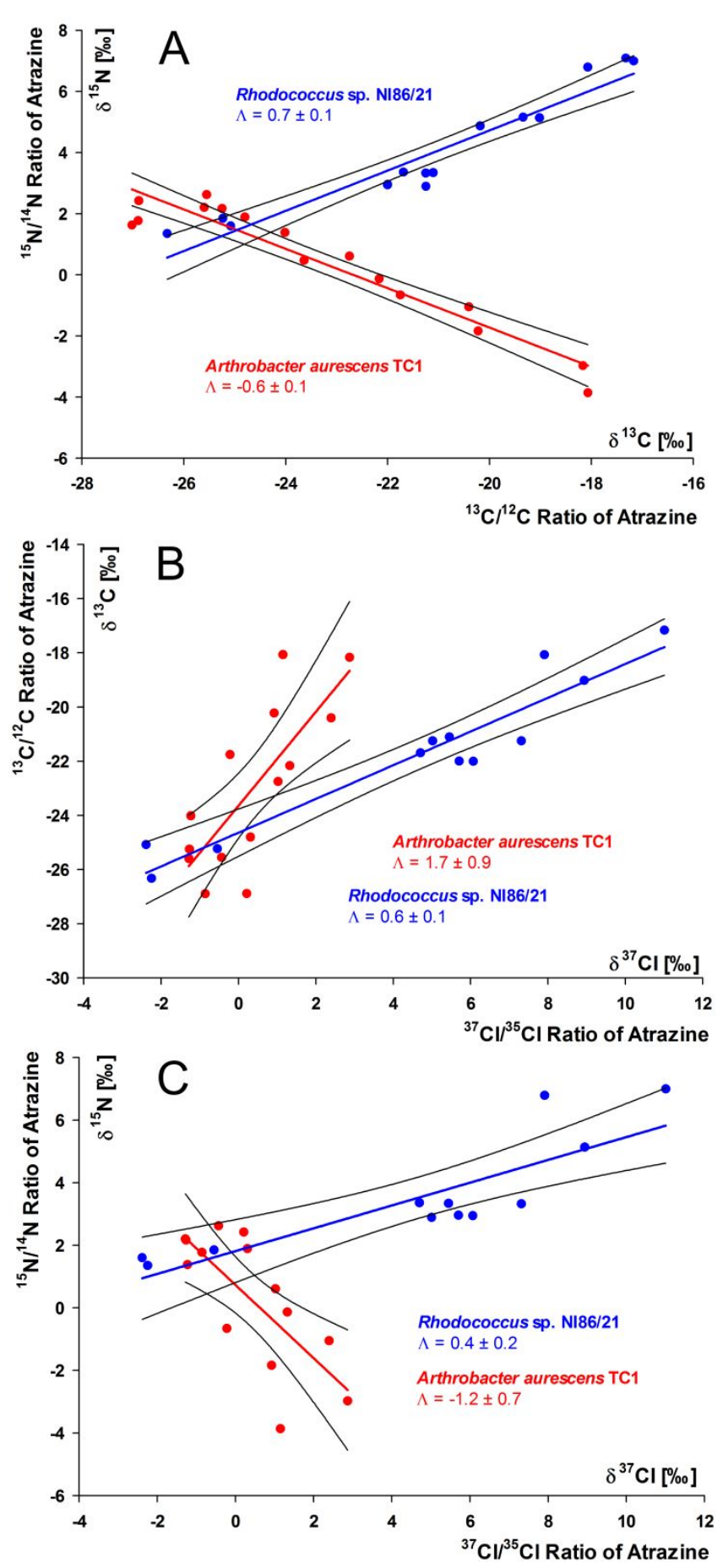

308 Figure 3. Isotope effects in microbial degradation of atrazine by $A$. aurescens TC1 (red) confidence intervals are given as values and as black lines next to the regression slopes). 
311 (A) Regression slopes of nitrogen and carbon isotope values $\left(\Lambda_{C / N}\right)$. (B) Regression 312 slopes of chlorine and carbon isotope values $\left(\Lambda_{\mathrm{C} / \mathrm{C}}\right)$. (C) Regression slopes of chlorine 313 and nitrogen isotope values $\left(\Lambda_{\mathrm{CI} / \mathrm{N}}\right)$.

314 Multi-element isotope approach. Results of chlorine isotope analysis were combined 315 with data for carbon and nitrogen isotope measurements in dual element isotope plots 316 (see Figure 3B and C). For hydrolysis with $A$. aurescens TC1 regression slopes of

$317 \wedge^{\text {Arthro }}{ }_{\mathrm{Cl} / \mathrm{C}}=1.7 \pm 0.9$ and $\wedge^{\text {Arthro }}{ }_{\mathrm{Cl} / \mathrm{N}}=-1.2 \pm 0.7$ were obtained. Oxidative dealkylation by 318 Rhodococcus sp. NI86/21 resulted in regression slopes of $\Lambda{ }^{\text {Rhodo }} \mathrm{Cl/C}=0.6 \pm 0.1$ and $319 \wedge^{\text {Rhodo }} \mathrm{CIN}=0.4 \pm 0.2$. Since the dual element isotope plots of chlorine and carbon and of 320 chlorine and nitrogen provide significantly different regression slopes for the respective 321 elements, they can provide an additional line of evidence to differentiate the two 322 degradation mechanisms of atrazine from each other.

323 Surprising mechanistic evidence from chlorine isotope effects. For degradation with

324 A. aurescens TC1, rather small chlorine isotope fractionation was observed $\left(\varepsilon_{\mathrm{Cl}}=-1.4\right.$

$325 \pm 0.6 \%$ ) despite the fact that the chlorine is cleaved off during hydrolysis (see Figure 1).

326 For oxidative dealkylation with Rhodococcus sp. NI86/21, the chlorine is not cleaved off 327 (see Figure 1), therefore, no or just a small chlorine isotope effect was expected. 328 However, here more pronounced chlorine isotope fractionation was observed $\left(\varepsilon_{\mathrm{Cl}}=-4.3\right.$ $329 \pm 1.8 \%$ ) 

compared to the $\mathrm{AKIE}_{\mathrm{Cl}}$ values of other studies focusing on the same degradation mechanisms. In addition, the $\mathrm{AKIE}_{\mathrm{Cl}}$ values were compared to the theoretical maximum Streitwieser Limit associated with the cleavage of a $\mathrm{C}-\mathrm{Cl}$ bond $\left(\mathrm{KIE}_{\mathrm{Cl}}=1.02\right)^{41-43}$ and to 334 the predictions of computational calculations (Table 2).

335 Table 1. AKIE $\mathrm{Cl}_{\mathrm{Cl}}$ values associated with atrazine degradation.

\begin{tabular}{|c|c|c|}
\hline Mechanism & $\mathrm{AKIE}_{\mathrm{Cl}}$ & Study \\
\hline \multicolumn{3}{|l|}{ Experimental Data } \\
\hline abiotic alkaline hydrolysis $\left(21^{\circ} \mathrm{C}\right)$ & $1.0069 \pm 0.0005$ & $\begin{array}{l}\text { Dybala-Defratyka et } \\
\text { al. }{ }^{35}\end{array}$ \\
\hline abiotic alkaline hydrolysis $\left(50^{\circ} \mathrm{C}\right)$ & $1.0009 \pm 0.0006$ & Grzybkowska et al. ${ }^{36}$ \\
\hline microbial hydrolysis ( $A$. aurescens $\mathrm{TC} 1)$ & $1.0014 \pm 0.0006^{*}$ & this study \\
\hline microbial dealkylation (Rhodococcus sp. NI86/21) & $1.0043 \pm 0.0018^{*}$ & this study \\
\hline \multicolumn{3}{|l|}{ Computational Data } \\
\hline $\begin{array}{l}\text { abiotic acidic/enzymatic hydrolysis (transition state } \\
\text { 1) }\end{array}$ & $\begin{array}{l}\text { range of } 1.0002 \text { to } \\
1.0011\end{array}$ & Grzybkowska et al. ${ }^{36}$ \\
\hline $\begin{array}{l}\text { abiotic acidic/enzymatic hydrolysis (transition state } \\
\text { 2) }\end{array}$ & 1.0099 & this study \\
\hline abiotic neutral hydrolysis & 1.0045 & this study \\
\hline abiotic alkaline hydrolysis & $\begin{array}{l}\text { range of } 1.0003 \text { to } \\
1.0014\end{array}$ & Grzybkowska et al. ${ }^{36}$ \\
\hline enzymatic hydrolysis & $\begin{array}{l}\text { range of } 0.9996 \text { to } \\
1.0003\end{array}$ & Szatkowski et al. ${ }^{44}$ \\
\hline $\begin{array}{l}\text { abiotic dealkylation (hydrogen atom transfer by } \\
\mathrm{MnO}_{4}^{-} \text {) }\end{array}$ & 0.9999 & this study \\
\hline abiotic dealkylation (hydride transfer by $\mathrm{H}_{3} \mathrm{O}^{+}$) & 0.9997 & this study \\
\hline
\end{tabular}

* calculated according to eq. 5 
337 For microbial hydrolysis of atrazine an experimental $\mathrm{AKIE}^{\text {Arthro }} \mathrm{Cl}$ value of 1.0014 $338 \pm 0.0006$ was calculated (see Table 1). Dybala-Defratyka et al. ${ }^{35}$ reported a more 339 pronounced AKIE ${ }^{\text {alk.hydrol. }}{ }_{\mathrm{Cl}}$ value of $1.0069 \pm 0.0005$ (see Table 1). However, that study ${ }^{35}$ was conducted in an abiotic alkaline solution at $21^{\circ} \mathrm{C}$ so that another hydrolysis pathway

341 was involved. Newer data reported a much smaller value of $\mathrm{AKIE}^{\text {alk.hydrol. }} \mathrm{Cl}=1.0009$ $342 \pm 0.0006^{36}$ for the same alkaline hydrolysis at $50{ }^{\circ} \mathrm{C}$. Later on it was confirmed that abiotic 343 alkaline hydrolysis performed earlier at $21^{\circ} \mathrm{C}$ resembles rather neutral than alkaline conditions ${ }^{36}$. 344 Table 2 illustrates the different computed mechanisms that lie at the heart of the 345 computational predictions. It shows the different mechanistic routes between the alkaline 346 (substitution of $\mathrm{Cl}$ without protonation of the atrazine ring) and the acidic/enzymatic 347 pathway characterized in Meyer et al. ${ }^{9}$ (substitution of $\mathrm{Cl}$ with protonation of the atrazine 348 ring) include different possible transition states. Chlorine KIEs are, among other factors ${ }^{45}$, 349 determined by the percent extension of the $\mathrm{C}-\mathrm{Cl}$ bond in the transition state. As this is 350 directly related to the structure of the transition state, it can be linked to the $\mathrm{C}-\mathrm{Cl}$ bond 351 orders (Table 2), which decrease in the studied hydrolysis reactions when the $\mathrm{C}$ - $\mathrm{Cl}$ bond 352 is more ruptured as compared to its length in the reactants, resulting in increased chlorine 353 KIEs. Previously performed computations ${ }^{36}$ and computations of this study mimicking 354 alkaline, acidic, and neutral conditions indicated that the largest $\mathrm{AKIE}_{\mathrm{Cl}}$ should be 355 expected under neutral conditions (except for transition state 2 of acidic/enzymatic 356 hydrolysis). Under neutral conditions the $\mathrm{C}-\mathrm{Cl}$ bond is elongated leading to a transition 357 state geometry which differs substantially from hydrolysis reactions promoted either by 
alkaline or acidic conditions (see Table 2). However, hydrolysis at neutral $\mathrm{pH}$ is too slow to be of relevance. Computational calculations taking into account the transition state structures at a molecular level predicted $\mathrm{AKIE}_{\mathrm{Cl}}$ values ranging from 0.9996 to 1.0014 for alkaline, acidic and enzymatic hydrolysis (see Table 1 and 2)36, 44 . Hence, on the mechanistic level, the computational studies predict that the formation of a Meisenheimer complex rather than the subsequent $\mathrm{C}-\mathrm{Cl}$ bond cleavage is the rate-determining step during the nucleophilic aromatic substitution reaction catalyzed by $\operatorname{TrzN}^{36,44}$. In both abiotic pathways the $\mathrm{C}-\mathrm{Cl}$ bond at the transition state of the rate determining step is almost intact giving rise to very small $\mathrm{AKIE}_{\mathrm{Cl}}$ (the computed bond orders for both alkaline and acidic hydrolysis are the same and equal to 1.03 , see also Table 2). In this study, we therefore observed a similarly small $\mathrm{AKIE}^{\text {Arthro }} \mathrm{Cl}$ value for enzymatic hydrolysis in A. aurescens TC1 which resembles acid-catalyzed hydrolysis rather than alkaline hydrolysis $^{9}$. Hence, the picture emerges that different hydrolytic pathways give rise to experimental $A K I E_{C I}$ values much lower than the Streitwieser Limit of $1.02^{41-43}$ indicating that the chlorine isotope effect is masked in all cases and that the $\mathrm{C}-\mathrm{Cl}$ bond cleavage is not the rate-determining step. Interestingly, this is in contrast to ametryn hydrolysis where strong sulphur isotope effects were observed in enzymatic hydrolysis by $\operatorname{Trz} \mathrm{N}^{17}$. Further experimental work, including degradation experiments with other strains, hydrolysis and crude enzyme experiments, will be required to further substantiate the picture on chlorine isotope effects observed in this study. For the moment, since chlorine isotope effects were found to be masked, we must conclude, however, that information from chlorine isotope 
379 analysis alone would not be enough to differentiate the different reaction mechanisms.

380 This illustrates the importance of analyzing more than one element for mechanistic 381 differentiation. 


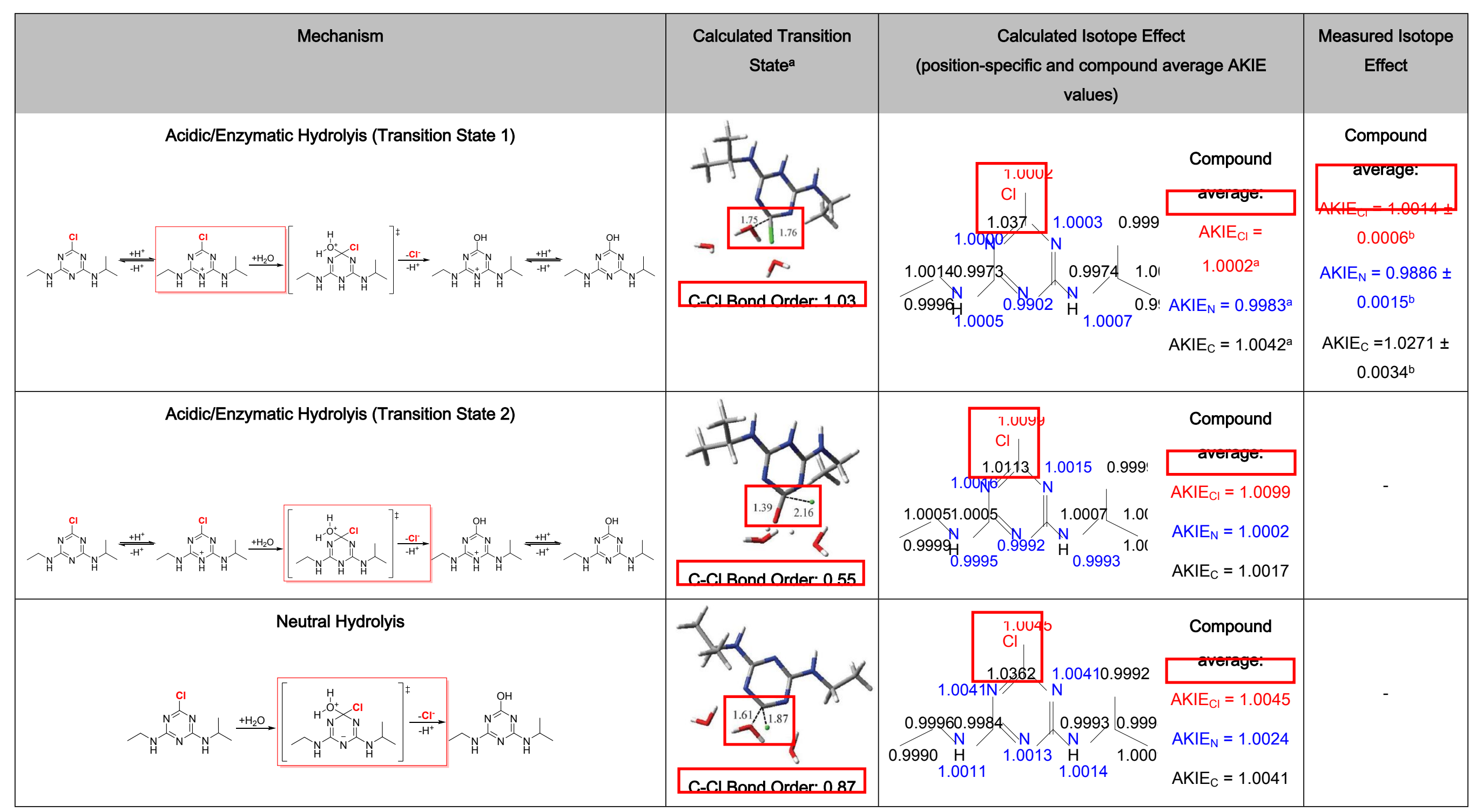



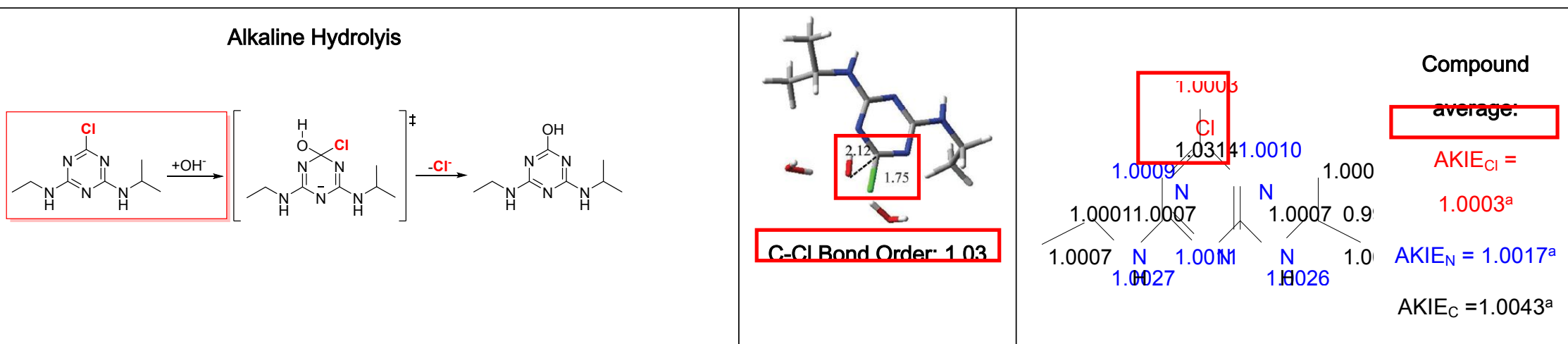

Compound

average:

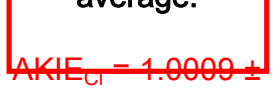

$0.0006^{a}$

$\mathrm{AKIE}_{\mathrm{N}}=1.001 \pm$ $0.000^{c}$

AKIE $_{C}=1.031 \pm$ $0.003^{c}$

${ }^{a}$ taken from Grzybkowska et al. ${ }^{36},{ }^{b}$ calculated according to eq. 5 with $\mathrm{n}=5$ for $\mathrm{N}$ and $\mathrm{n}=8$ for $\mathrm{C},{ }^{\mathrm{c}}$ taken from Meyer et al. ${ }^{9}$

386 

the reaction mechanism, Meyer et al. ${ }^{16}$ concluded that oxidative dealkylation of atrazine with Rhodococcus sp. NI86/21 is initiated by hydrogen atom transfer based on the observed product distribution and the carbon and nitrogen isotope effects. Hydrogen atom transfer leads directly to a homolytic cleavage of the $\mathrm{C}-\mathrm{H}$ bond adjacent to the nitrogen atom ( $\alpha$-position of the ethyl or isopropyl group) producing a relative unstable 1,1aminoalcohol which is then further transformed to DEA or DIA ${ }^{16}$. In parallel, two additional products could be detected which were formed by oxidation of the $\mathrm{C}-\mathrm{H}$ bond in the $\beta$ position of the ethyl or isopropyl group. For this mechanistic pathway, chlorine isotope effects would be expected to be rather small since the chlorine is not involved in the reaction steps. The closed mass balance of the concentration analysis (see Figure S5 in the $\mathrm{SI}$ ) of this study and the results of product distribution of Meyer et al. ${ }^{16}$ also indicate 399 that there is no $\mathrm{C}-\mathrm{Cl}$ bond cleavage taking place since corresponding hydrolysis products 400 were not detected. Furthermore, our computations for hydrogen atom transfer at a 401 catalytic center mimicking cytochrome P450 predicted no chlorine isotope effect 402 (AKIE hydro.atom trans. ${ }_{\mathrm{Cl}}=0.9999$, see Table 1). Hydride transfer promoted by the hydronium 403 ion also resulted in no chlorine isotope effect (AKIE hydride trans. ${ }_{\mathrm{Cl}}=0.9997$, see Table 1$)$. At 404 previously located transition state structures for these two reactions ${ }^{16}$ the carbon-chlorine 405 bond remains intact and no stretching of this bond is involved in the reaction coordinate 406 (hydrogen transfer) mode. The observed more pronounced AKIE ${ }^{\text {Rhodo }}{ }_{\mathrm{Cl}}$ value of 1.0043 $407 \pm 0.0018$ in this study (see Table 1) could, therefore, be indicative of isotope effects 
caused by enzymatic interactions. Meyer et al. ${ }^{16}$ proposed that for oxidative dealkylation no selectivity itself is observed, however, the preferred oxidation of the a-position over the $\beta$-position could be explained by steric factors of the catalyzing enzyme which could

411 have an influence on the transformation pathway. Thus, the sensitive chlorine isotope

412 effect, which is observed even though the $\mathrm{C}-\mathrm{Cl}$ bond is not cleaved during degradation,

413 can be interpreted as an indicator that non-covalent interactions between the 414 cytochrome P450 complex and the chlorine cause significant chlorine isotope 415 fractionation ${ }^{46}$.

416 CONCLUSION

417 Since atrazine is frequently detected in groundwater systems, major efforts should be 418 put into understanding its environmental fate. We provide an approach to 3D-isotope (C, $419 \mathrm{~N}, \mathrm{Cl}$ ) analysis of atrazine and explored isotope fractionation in different transformation 420 pathways. Together, this provides the basis to more confidently assess sources and 421 degradation of atrazine in the environment. Specifically, we demonstrated that 422 pronounced changes in chlorine isotope values are not an indicator of microbial hydrolysis 423 (as one might have expected without knowledge of our experimental data), but 424 surprisingly - rather of oxidative dealkylation. Therefore, although trends are different 425 than expected, they can nonetheless be used for a more confident identification of 426 different sources and transformation pathways in field samples. Regarding the sensitivity 427 of chlorine isotope effects, our study demonstrates the importance of performing 
441 There are no conflicts to declare.

\section{CONFLICT OF INTEREST}

\section{ACKNOWLEDGMENT}

controlled laboratory experiments before applying the approach in the field. Specifically, in other cases chlorine isotope fractionation can be much more pronounced than observed for atrazine in this study. Large chlorine isotope effects were observed in proofof-principle experiments by Ponsin et al. ${ }^{20}$ studying hydrolytic dechlorination of Smetolachlor, an herbicide containing also only one chlorine atom. Here preliminary data suggest a large chlorine isotope effect of $\varepsilon_{C l}=-9.7 \pm 2.9 \%$ for abiotic alkaline hydrolysis. Therefore, in the case of other substances chlorine isotope effects can be even more sensitive indicators of degradation provided that the $\mathrm{C}-\mathrm{Cl}$ bond cleavage occurs in the rate-determining step of a reaction. Further, gaining deeper insights into these chemical processes is the basis for understanding the biotic catalysis of organic micropollutant degradation. This, in turn, is essential for identifying and developing optimized strategies for micropollutant removal in order to make successful bioremediation possible.

This work was supported by the Swiss National Science Foundation (SNSF, Grant CRSII2_141805), the German Israeli Foundation for Scientific Research and Development (GIF, Grant I-251-307.4-2013) and the National Science Center in Poland (Sonata BIS grant UMO-2014/14/E/ST4/00041). We thank PLGrid Infrastructure 
(Poland) for computer resources and Armin Meyer for his advice regarding the microbial degradation experiments.

449

450

451

452

\section{REFERENCES}

1. H. Gysin and E. Knusli, Chemistry and herbicidal properties of triazine derivatives, Adv. in Pest Control Res., 1960, 3, 289-353.

2. EPA, Pesticides Industry Sales and Usage: 2008-2012 Market Estimates, US Environmental Protection Agency, Washington (DC), 2017.

3. European Commission, Commission decision of 10 March 2004 concerning the non-inclusion of atrazine in Annex I to Council Directive 91/414/EEC and the withdrawal of authorisations for plant protection products containing this active substance., Official Journal of the European Union, 2004, 78, 53-55.

4. R. Loos, G. Locoro, S. Comero, S. Contini, D. Schwesig, F. Werres, P. Balsaa, O. Gans, S. Weiss, L. Blaha, M. Bolchi and B. M. Gawlik, Pan-European survey on the occurrence of selected polar organic persistent pollutants in ground water, Water Res., 2010, 44, 4115-4126.

5. D. Vonberg, J. Vanderborght, N. Cremer, T. Pütz, M. Herbst and H. Vereecken, 20 years of long-term atrazine monitoring in a shallow aquifer in western Germany, Water Res., 2014, 50, 294-306.

6. S. Singh, V. Kumar, A. Chauhan, S. Datta, A. B. Wani, N. Singh and J. Singh, Toxicity, degradation and analysis of the herbicide atrazine, Environ. Chem. Lett., 2018, 16, 211-237.

7. S. Kern, H. P. Singer, J. Hollender, R. P. Schwarzenbach and K. Fenner, Assessing exposure to transformation products of soil-applied organic contaminants in surface water: comparison of model predictions and field data, Environ. Sci. Technol., 2011, 45, 2833-2841.

8. C. Moreau-Kervevan and C. Mouvet, Adsorption and desorption of atrazine, deethylatrazine, and hydroxyatrazine by soil components, J. Environ. Qual. , 1998, 27, 46-53. 
9. A. H. Meyer, H. Penning and $\mathrm{M}$. Elsner, $\mathrm{C}$ and $\mathrm{N}$ isotope fractionation suggests similar mechanisms of microbial atrazine transformation despite involvement of different Enzymes (AtzA and TrzN), Environ. Sci. Technol., 2009, 43, 8079-8085.

10. A. H. Meyer and M. Elsner, $13 \mathrm{C} / 12 \mathrm{C}$ and $15 \mathrm{~N} / 14 \mathrm{~N}$ Isotope Analysis To Characterize Degradation of Atrazine: Evidence from Parent and Daughter Compound Values, Environ. Sci. Technol., 2013, 47, 6884-6891.

11. A. H. Meyer, H. Penning, H. Lowag and M. Elsner, Precise and accurate compound specific carbon and nitrogen isotope analysis of atrazine: critical role of combustion oven conditions, Environ. Sci. Technol., 2008, 42, 7757-7763.

12. S. Reinnicke, D. Juchelka, S. Steinbeiss, A. H. Meyer, A. Hilkert and M. Elsner, Gas chromatography-isotope ratio mass spectrometry (GC-IRMS) of recalcitrant target compounds: performance of different combustion reactors and strategies for standardization, Rapid. Commun. Mass. Sp., 2012, 26, 1053-1060.

13. K. Schreglmann, M. Hoeche, S. Steinbeiss, S. Reinnicke and M. Elsner, Carbon and nitrogen isotope analysis of atrazine and desethylatrazine at sub-microgram per liter concentrations in groundwater, Anal. Bioanal. Chem., 2013, 405, 28572867.

14. T. C. Schmidt, L. Zwank, M. Elsner, M. Berg, R. U. Meckenstock and S. B. Haderlein, Compound-specific stable isotope analysis of organic contaminants in natural environments: a critical review of the state of the art, prospects, and future challenges, Anal. Bioanal. Chem., 2004, 378, 283-300.

15. M. Elsner, Stable isotope fractionation to investigate natural transformation mechanisms of organic contaminants: principles, prospects and limitations, $\mathrm{J}$. Environ. Monit., 2010, 12, 2005-2031.

16. A. H. Meyer, A. Dybala-Defratyka, P. J. Alaimo, I. Geronimo, A. D. Sanchez, C. J. Cramer and M. Elsner, Cytochrome P450-catalyzed dealklyation of atrazine by Rhodococcus sp. strain NI86/21 involves hydogen atom transfer rather than single electorn transfer, Dalton Trans., 2014, 43, 12111-12432.

17. H. K. V. Schürner, J. L. Seffernick, A. Grzybkowska, A. Dybala-Defratyka, L. P. Wackett and M. Elsner, Characteristic Isotope Fractionation Patterns in s- 
Triazine Degradation Have Their Origin in Multiple Protonation Options in the sTriazine Hydrolase TrzN, Environ. Sci. Technol., 2015, 49, 3490-3498.

18. T. B. Hofstetter and M. Berg, Assessing transformation processes of organic contaminants by compound-specific stable isotope analysis, TrAC, Trends Anal. Chem., 2011, 30, 618-627.

19. J. Renpenning, A. Horst, M. Schmidt and M. Gehre, Online isotope analysis of $37 \mathrm{Cl} / 35 \mathrm{Cl}$ universally applied for semi-volatile organic compounds using GC-MCICPMS, J. Anal. At. Spectrom., 2018, 33, 314-321.

20. V. Ponsin, C. Torrentó, C. Lihl, M. Elsner and D. Hunkeler, Compound-specific chlorine isotope analysis of the herbicides atrazine, acetochlor and metolachlor, Anal. Chem., 2019, 91, 14290-14298.

21. C. Lihl, L. M. Douglas, S. Franke, A. Pérez-de-Mora, A. H. Meyer, M. Daubmeier, E. A. Edwards, I. Nijenhuis, B. Sherwood Lollar and M. Elsner, Mechanistic Dichotomy in Bacterial Trichloroethene Dechlorination Revealed by Carbon and Chlorine Isotope Effects, Environ. Sci. Technol., 2019, 53, 4245-4254.

22. L. E. Erickson, Degradation of atrazine and related s-triazines, Crit. Rev. Env. Con., 1989, 19, 1-14.

23. H. M. LeBaron, J. E. McFarland and O. C. Burnside, The triazine herbicides, Elsevier, Oxford, 1 edn., 2008.

24. L. C. Strong, C. Rosendahl, G. Johnson, M. J. Sadowsky and L. P. Wackett, Arthrobacter aurescens TC1 metabolizes diverse s-triazine ring compounds, Appl. Environ. Microbiol., 2002, 68, 5973-5980.

25. K. Sajjaphan, N. Shapir, L. P. Wackett, M. Palmer, B. Blackmon, J. Tomkins and M. J. Sadowsky, Arthrobacter aurescens TC1 Atrazine Catabolism Genes trzN, $a t z B$, and atzC Are Linked on a 160-Kilobase Region and Are Functional in Escherichia coli, Appl. Environ. Microbiol., 2004, 70, 4402-4407.

26. I. Nagy, F. Compernolle, K. Ghys, J. Vanderleyden and R. De Mot, A single cytochrome P-450 system is involved in degradation of the herbicides EPTC (Sethyl dipropylthiocarbamate) and atrazine by Rhodococcus sp. strain NI86/21, Appl. Environ. Microbiol., 1995, 61, 2056-2060. 
27. M. Elsner, L. Zwank, D. Hunkeler and R. P. Schwarzenbach, A new concept linking observable stable isotope fractionation to transformation pathways of organic pollutants, Environ. Sci. Technol., 2005, 39, 6896-6916.

28. L. Zwank, M. Berg, M. Elsner, T. C. Schmidt, R. P. Schwarzenbach and S. B. Haderlein, New evaluation scheme for two-dimensional isotope analysis to decipher biodegradation processes: application to groundwater contamination by MTBE, Environ. Sci. Technol., 2005, 39, 1018-1029.

29. S. Reinnicke, A. Simonsen, S. R. Sørensen, J. Aamand and M. Elsner, C and N Isotope Fractionation during Biodegradation of the Pesticide Metabolite 2,6Dichlorobenzamide (BAM): Potential for Environmental Assessments, Environ. Sci. Technol., 2012, 46, 1447-1454.

30. T. Gilevska, M. Gehre and H. H. Richnow, Multidimensional isotope analysis of carbon, hydrogen and oxygen as tool for identification of the origin of ibuprofen, J. Pharm. Biomed. Anal., 2015, 115, 410-417.

31. J. Palau, O. Shouakar-Stash, S. Hatijah Mortan, R. Yu, M. Rosell, E. MarcoUrrea, D. L. Freedman, R. Aravena, A. Soler and D. Hunkeler, Hydrogen Isotope Fractionation during the Biodegradation of 1,2-Dichloroethane: Potential for Pathway Identification Using a Multi-element $(\mathrm{C}, \mathrm{Cl}$, and $\mathrm{H})$ Isotope Approach, Environ. Sci. Technol., 2017, 51, 10526-10535.

32. S. Franke, C. Lihl, J. Renpenning, M. Elsner and I. Nijenhuis, Triple-element compound-specific stable isotope analysis of 1,2-dichloroethane for characterization of the underlying dehalogenation reaction in two Dehalococcoides mccartyi strains, FEMS Microbiol. Ecol., 2017, 93, fix137.

33. T. Kuder, B. M. van Breukelen, M. Vanderford and P. Philp, 3D-CSIA: Carbon, Chlorine, and Hydrogen Isotope Fractionation in Transformation of TCE to Ethene by a Dehalococcoides Culture, Environ. Sci. Technol., 2013, 47, 96689677.

34. B. Heckel, K. McNeill and M. Elsner, Chlorinated Ethene Reactivity with Vitamin B12 Is Governed by Cobalamin Chloroethylcarbanions as Crossroads of Competing Pathways, ACS Catal., 2018, 8, 3054-3066. 
35. A. Dybala-Defratyka, L. Szatkowski, R. Kaminski, M. Wujec, A. Siwek and P. Paneth, Kinetic isotope effects on dehalogenations at an aromatic carbon, Environ. Sci. Technol., 2008, 42, 7744-7750.

36. A. Grzybkowska, R. Kaminski and A. Dybala-Defratyka, Theoretical predictions of isotope effects versus their experimental values for an example of uncatalyzed hydrolysis of atrazine, Phys. Chem. Chem. Phys., 2014, 16, 15164-15172.

37. C. Lihl, J. Renpenning, S. Kümmel, F. Gelman, H. K. V. Schürner, M. Daubmeier, B. Heckel, A. Melsbach, A. Bernstein, O. Shouakar-Stash, M. Gehre and M. Elsner, Toward Improved Accuracy in Chlorine Isotope Analysis: Synthesis Routes for In-House Standards and Characterization via Complementary Mass Spectrometry Methods, Anal. Chem., 2019, 91, 12290-12297.

38. D. Hunkeler, R. U. Meckenstock, B. Sherwood Lollar, T. Schmidt, J. Wilson, T. Schmidt and J. Wilson, A Guide for Assessing Biodegradation and Source Identification of Organic Ground Water Contaminants using Compound Specific Isotope Analysis (CSIA), O. o. R. a. Development Report PA 600/R-08/148 | December 2008 | www.epa.gov/ada, US EPA, Oklahoma, USA, 2008.

39. J. Bigeleisen, The relative reaction velocities of isotopic molecules, J. Chem. Phys., 1949, 17, 675-679.

40. V. Anisimov and P. Paneth, ISOEFF98. A program for studies of isotope effects using Hessian modifications, J. Math. Chem., 1999, 26.

41. A. Streitwieser Jr, R. Jagow, R. Fahey and S. Suzuki, Kinetic isotope effects in the acetolyses of deuterated cyclopentyl tosylates1, 2, J. Am. Chem. Soc., 1958, 80, 2326-2332.

42. K. Świderek and P. Paneth, Extending limits of chlorine kinetic isotope effects, $J$. Org. Chem., 2012, 77, 5120-5124.

43. L. Szatkowski and A. Dybala-Defratyka, A computational study on enzymatically driven oxidative coupling of chlorophenols: An indirect dehalogenation reaction, Chemosphere, 2013, 91, 258-264.

44. L. Szatkowski, R. N. Manna, A. Grzybkowska, R. Kamiński, A. Dybala-Defratyka and P. Paneth, in Methods in enzymology, Elsevier, 2017, vol. 596, pp. 179-215. 
595 45. A. Dybala-Defratyka, M. Rostkowski, O. Matsson, K. C. Westaway and P. Paneth, A New Interpretation of Chlorine Leaving Group Kinetic Isotope Effects; A Theoretical Approach, J. Org. Chem., 2004, 69, 4900-4905.

46. A. Siwek, R. Omi, K. Hirotsu, K. Jitsumori, N. Esaki, T. Kurihara and P. Paneth, Binding modes of DL-2-haloacid dehalogenase revealed by crystallography, modeling and isotope effects studies, Arch. Biochem. Biophys., 2013, 540, 2632. 